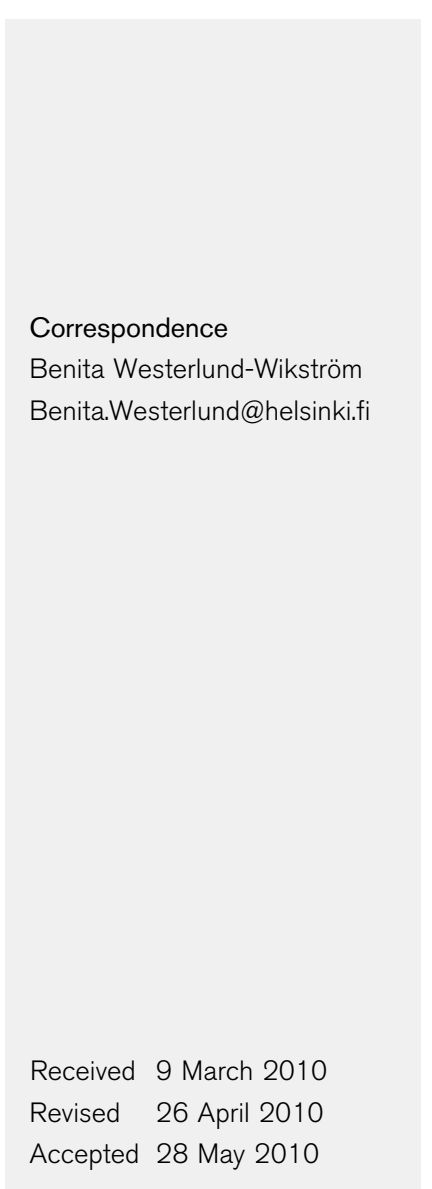

\title{
Mat fimbriae promote biofilm formation by meningitis-associated Escherichia coli
}

\author{
Timo A. Lehti, ${ }^{1}$ Philippe Bauchart, ${ }^{2}$ Johanna Heikkinen, ${ }^{1}$ Jörg Hacker, ${ }^{2,3}$ \\ Timo K. Korhonen, ${ }^{1}$ Ulrich Dobrindt ${ }^{2}$ and Benita Westerlund-Wikström ${ }^{1}$ \\ ${ }^{1}$ General Microbiology, Department of Biosciences, Fl-00014 University of Helsinki, Finland \\ ${ }^{2}$ Institute for Molecular Infection Biology, University of Würzburg, D-97080 Würzburg, Germany \\ ${ }^{3}$ Robert Koch-Institute, D-13353 Berlin, Germany
}

\begin{abstract}
The mat (or ecp) fimbrial operon is ubiquitous and conserved in Escherichia coli, but its functions remain poorly described. In routine growth media newborn meningitis isolates of $E$. coli express the meningitis-associated and temperature-regulated (Mat) fimbria, also termed $E$. coli common pilus (ECP), at $20^{\circ} \mathrm{C}$, and here we show that the six-gene (matABCDEF)-encoded Mat fimbria is needed for temperature-dependent biofilm formation on abiotic surfaces. The matBCDEF deletion mutant of meningitis $E$. coli IHE 3034 was defective in an early stage of biofilm development and consequently unable to establish a detectable biofilm, contrasting with IHE 3034 derivatives deleted for flagella, type 1 fimbriae or S-fimbriae, which retained the wild-type biofilm phenotype. Furthermore, induced production of Mat fimbriae from expression plasmids enabled biofilm-deficient $E$. coli $\mathrm{K}-12$ cells to form biofilm at $20^{\circ} \mathrm{C}$. No biofilm was detected with IHE 3034 or MG1655 strains grown at $37{ }^{\circ} \mathrm{C}$. The surface expression of Mat fimbriae and the frequency of Mat-positive cells in the IHE 3034 population from $20^{\circ} \mathrm{C}$ were high and remained unaltered during the transition from planktonic to biofilm growth and within the matured biofilm community. Considering the prevalence of the highly conserved mat locus in E. coligenomes, we hypothesize that Mat fimbria-mediated biofilm formation is an ancestral characteristic of $E$. coli.
\end{abstract}

\section{INTRODUCTION}

Escherichia coli is a multifaceted bacterium that colonizes the mammalian intestine as a harmless commensal but also causes a repertoire of intestinal and extraintestinal infectious diseases (Dobrindt, 2005) and survives in the environment (Savageau, 1983). E. coli from the mother and/or the surrounding environment are generally among the earliest colonizers in the oxygenous neonatal gut. During the first months of life a succession of bacterial populations progresses to a complex, more stable and adult-like microbial community dominated by strict anaerobes (Adlerberth \& Wold, 2009). However, some E. coli strains are able to persist as a member of the normal microbiota and constitute a major portion of the facultative intestinal flora on adult mucosal surfaces. E. coli also frequently colonizes anatomical locations outside the gastrointestinal tract, e.g. vagina and urinary bladder (Obata-Yasuoka et al., 2002; Rosen et al., 2007). The population structure of E. coli is

Abbreviations: CV, crystal violet; ECP, E. coli common pilus; Mat, meningitis-associated and temperature-regulated; NMEC, newborn meningitis Escherichia coli; SIP, surface-influenced planktonic.

The GenBank/EMBL/DDBJ accession number for the mat operon region of the E. coli IHE 3034 chromosome reported in this paper is HM102365. largely clonal (Ochman \& Selander, 1984; Selander et al., 1986), and isolates are frequently categorized into distinct pathogroups according to specific combinations of phenotypic traits. Based on multilocus enzyme electrophoresis, $E$. coli strains fall into four main phylogenetic groups (designated A, B1, B2 and D), each containing varying proportions of different pathogroups and non-pathogens. $E$. coli strains resident in childhood and adult microbiota commonly include pathogenic variants (Sarff et al., 1975; Siitonen, 1992), predominantly belonging to the virulenceassociated phylogenetic group B2 (Nowrouzian et al., 2005; Obata-Yasuoka et al., 2002; Zhang et al., 2002). Despite their primarily asymptomatic colonization, these B2 strains are able to induce various diseases, such as neonatal meningitis, urinary tract infections, sepsis and pneumonia, after entering into extraintestinal sites in both normal and compromised hosts (Picard et al., 1999; Russo \& Johnson, 2000). This implies that the normal flora is an important reservoir for extraintestinal pathogenic E. coli strains.

The evolutionary success of E. coli relies in part on the ability to express surface proteins that mediate cellular interactions on biotic and abiotic surfaces. Expression of meningitis-associated and temperature-regulated (Mat) fimbriae was originally detected in the genetically conserved O18ac: K1 : H7 clonal group of human newborn meningitis 
E. coli (NMEC) isolates cultivated at low temperature (Pouttu et al., 2001). Recently, expression of the fimbria, also called E. coli common pilus (ECP; Rendón et al., 2007), was found to be wide spread in pathogenic and nonpathogenic E. coli strains and to contribute, to a variable extent, to E. coli adherence onto cultured epithelial cells (Blackburn et al., 2009; Lasaro et al., 2009; Rendón et al., 2007; Saldaña et al., 2009); however, the adhesin or the receptor have not yet been identified. The mat (or ecp) genes are wide spread and conserved in E. coli, and it appears that their regulatory mechanisms are modulated by multiple environmental cues and differ among clonal groups of $E$. coli (Blackburn et al., 2009; Pouttu et al., 2001; Rendón et al. 2007).

A matrix-enclosed, organized-community lifestyle in a biofilm is a common mode of growth for many bacterial species that inhabit diverse environments (Hall-Stoodley et al., 2004). Biofilm formation allows bacteria to survive in stressful conditions and facilitates transmission to new niches. E. coli have developed a spectrum of sophisticated and finely controlled pathways to promote growth in such surface-bound communal structures (Beloin et al., 2008; Van Houdt \& Michiels, 2005). The early stages of biofilm development often involve employment of flagellamediated motility for reversible and initial attachment onto a surface (Pratt \& Kolter, 1998; Wood et al., 2006). Production of other surface organelles, including $\mathrm{F}$ pili, type 1 fimbriae and curli, is needed for irreversible attachment to strengthen the adhesion (Ghigo, 2001; Pratt \& Kolter, 1998; Reisner et al., 2003; Vidal et al., 1998). In this study, we analysed the mat cluster of NMEC for its contribution to biofilm formation and describe a function of Mat fimbriae as a biofilm-promoting factor.

\section{METHODS}

Strains, plasmids and growth conditions. E. coli strains and plasmids used in this study are listed in Table 1 . All cultivations were performed without agitation at 20 or $37{ }^{\circ} \mathrm{C}$ in Luria-Bertani (LB) broth or in M63 medium [minimal M63 salts (Pardee et al., 1959) supplemented with $0.4 \%$ glucose and $1 \%$ Casamino acids]. When necessary, media were supplemented with ampicillin $100 \mu \mathrm{g} \mathrm{ml}{ }^{-1}$,

Table 1. E. coli strains and plasmids used in this study

\begin{tabular}{|c|c|c|}
\hline Strain or plasmid & Genotype or description & Source or reference \\
\hline \multicolumn{3}{|l|}{ E. coli strains } \\
\hline IHE 3034-Rif & Rifampicin-resistant IHE $3034, \mathrm{O} 18: \mathrm{K} 1: \mathrm{H} 7$ & Pouttu et al. (2001) \\
\hline IHE 3034-91 & IHE $3034-$ Rif $\Delta m a t B(+61$ to +528 bp from the ATG of matB) & This study \\
\hline IHE 3034-92 & IHE 3034-Rif $\Delta m a t C(+61$ to +609 bp from the ATG of matC) & This study \\
\hline IHE 3034-93 & IHE 3034 -Rif $\Delta m a t D(+61$ to +2466 bp from the ATG of matD) & This study \\
\hline IHE 3034-95 & IHE 3034-Rif $\Delta m a t F(+151$ to +696 bp from the ATG of matF) & This study \\
\hline IHE 3034-96 & $\begin{array}{l}\text { IHE } 3034-\text { Rif } \triangle m a t B C D E F(+61 \text { bp from the ATG of matB to }+753 \text { bp from } \\
\text { the ATG of matF) }\end{array}$ & This study \\
\hline IHE 3034-97 & IHE 3034-Rif $\triangle$ matBCDEF complemented with matBCDEF & This study \\
\hline IHE 3034-Sm & Streptomycin-resistant IHE 3034, O18: K1:H7 & Pouttu et al. (1999) \\
\hline IHE 3034-2 & IHE 3034-Sm fimA: : cat & Pouttu et al. (1999) \\
\hline IHE 3034-99 & IHE 3034-Sm fimA:: cat sfaA:: Gm fliC:: sat $\Delta$ matB & This study \\
\hline ABU38 & Asymptomatic bacteriuria strain & Lindberg et al. (1975) \\
\hline MG1655 & $\mathrm{K}-12$ & Blattner et al. (1997) \\
\hline S17-1 $\lambda$ pir & recA thi pro hsdR RP4-2-Tc:: Mu Km::Tn7 $\lambda$ pir & Simon et al. (1983) \\
\hline \multicolumn{3}{|l|}{ Plasmids } \\
\hline pGP704 & Suicide vector, pir-dependent & Miller \& Mekalanos (1988) \\
\hline pCVD442 & Suicide vector, pir-dependent, $s a c B$ & Donnenberg \& Kaper (1991) \\
\hline pSE380 & Expression vector, $\operatorname{trc}$ promoter & Invitrogen \\
\hline pMAT6 & IHE 3034 matBCDEF in pSE380 & Pouttu et al. (2001) \\
\hline pMAT10 & IHE 3034 matB in pSE380 & Pouttu et al. (2001) \\
\hline pMAT12 & IHE 3034 matC in pSE380 & This study \\
\hline
\end{tabular}


chloramphenicol $25 \mu \mathrm{g} \mathrm{ml}{ }^{-1}$, gentamicin $30 \mu \mathrm{g} \mathrm{ml} l^{-1}$, rifampicin $75 \mu \mathrm{g} \mathrm{ml}^{-1}$, streptomycin $100 \mu \mathrm{g} \mathrm{ml}^{-1}$, streptothricin $100 \mu \mathrm{g} \mathrm{ml}^{-1}$ or tetracycline $12.5 \mu \mathrm{g} \mathrm{ml}^{-1}$. Induction of mat genes in recombinant $E$. coli strains was done with $5 \mu \mathrm{M}$ IPTG.

Construction of chromosomal mutants. In-frame deletion of the entire matBCDEF region and each putative mat gene on the chromosome of the spontaneously Rif-resistant strain IHE 3034-Rif was performed by site-specific mutagenesis with the pir-dependent suicide vector pCVD442 essentially as described by Mobley et al. (1993). Briefly, the $5^{\prime}$ and $3^{\prime}$ flanking sequences of each deletion site were amplified by PCR from IHE 3034 chromosomal DNA with Pfu polymerase (Promega), fused with each other by recombinant PCR and then inserted between the SacI and XbaI sites of the pCVD442. The resulting plasmids were introduced into IHE 3034-Rif by conjugation using the donor strain S17-1 $\lambda$ pir. After sucrose selection, the allelic exchanges were screened by PCR, and the correct deletions were verified by sequencing before testing of the mutants. Primers for the mutagenesis were designed on the basis of the mat region sequence of E. coli IHE 3034 (accession number HM102365), which was determined by using a commercially available sequencing service (DNA Sequencing and Genomics Laboratory, University of Helsinki, Finland). To obtain a fimA sfaA fliC matB quadruple mutant, the matB gene was deleted from the Sm-resistant strain IHE 3034-79, a fimA sfaA fliC derivative, as described above. The fliC gene of IHE 3034-Sm was inactivated by allelic exchange with a fliC: : cat cassette using the pir-dependent suicide vector pGP704 essentially as described before (Pouttu et al., 1999).

In the matBCDEF mutant strain, the deletion was complemented by insertion of the wild-type alleles back into the chromosomal deletion site by reverse allelic exchange using pCVD442.

Cloning of mat genes. For in trans complementation of the individual mat deletion derivatives, plasmids encoding MatC, MatD, MatE and MatF were constructed in the inducible pSE380 vector as described earlier (Pouttu et al., 2001). Briefly, the genes were amplified by PCR from IHE 3034 chromosomal DNA with Pfu polymerase (Promega), cloned into the EcoRI-SalI site of pSE380 under the inducible $\operatorname{trc}$ promoter, and the nucleotide sequences were verified by sequencing. Plasmid construct pMAT20 was similarly made by cloning matBCDEF genes from MG1655 chromosomal DNA into pSE380, and confirmed by partial sequencing. The plasmids were introduced into the different $E$. coli hosts by $\mathrm{CaCl}_{2}$ transformation or by electroporation (Sambrook \& Russell, 2001).

Biofilm formation. Biofilm formation on plastic surfaces was measured using the microtitre plate assay system, performed basically as described by Genevaux et al. (1996). Briefly, the cells were grown for $48 \mathrm{~h}$ in M63 medium at 20 or $37^{\circ} \mathrm{C}$, diluted in M63 medium $(1: 200, \mathrm{v} / \mathrm{v})$ and then $160 \mu \mathrm{l}$ of each suspension was added into the wells of a PVC microtitre plate (Falcon). After $48 \mathrm{~h}$ of growth at 20 or $37{ }^{\circ} \mathrm{C}$, adherent cell layers were washed twice with PBS, pH 7.1, dried, stained with $0.1 \%$ crystal violet $(\mathrm{CV})$ for $10 \mathrm{~min}$ and again washed twice with PBS and dried. To quantify biofilm formation the CV stain was solubilized in ethanol/acetone $(80: 20, \mathrm{v} / \mathrm{v})$, diluted $1: 4$ in ethanol/acetone $(80: 20, \mathrm{v} / \mathrm{v})$ and the absorbance at $595 \mathrm{~nm}$ was measured in an ELISA recorder (Multiskan EX, Thermo Scientific). The mean absorbance from six wells was calculated for each assay. We also used this method to quantify biofilm formation on polystyrene microtitre plates (Nunc) and glass coverslips (Menzel-Gläser).

Initial attachment. To assess the initial attachment of IHE 3034-Rif derivatives onto PVC surfaces, the strains were grown in static M63 medium for $48 \mathrm{~h}$ at $20{ }^{\circ} \mathrm{C}$, diluted in $\mathrm{M} 63$ to an $\mathrm{OD}_{600}$ value of 0.1 , and then $500 \mu \mathrm{l}$ of each suspension was added to a 24 -well plate containing sterile PVC tabs $\left(1 \times 1 \mathrm{~cm}^{2}\right)$ and incubated at $20{ }^{\circ} \mathrm{C}$. After various time intervals the tabs were rinsed twice with PBS, fixed with $3.5 \%$ paraformaldehyde in PBS for $10 \mathrm{~min}$, immunostained (see below) and examined by epifluorescence microscopy (Olympus BX50). The numbers of bacteria in 20 randomly chosen microscopic fields of $10^{3} \mu \mathrm{m}^{2}$ were determined. The initial attachment to PVC was also tested by using the CV-based method of O'Toole \& Kolter (1998), with the following modifications. The strains were grown statically in M63 medium for $48 \mathrm{~h}$ at $20{ }^{\circ} \mathrm{C}$, diluted in fresh M63 to an $\mathrm{OD}_{600}$ value of 0.1 or 1.0 , and $160 \mu \mathrm{l}$ of each suspension was inoculated into the wells of a 96-well microtitre plate. After incubation for $1 \mathrm{~h}$ at $20{ }^{\circ} \mathrm{C}$, the adhered cells were washed twice with $\mathrm{PBS}$ and quantified by CV staining, as described above.

Detection of Mat fimbriae expression by whole-cell ELISA. Polyclonal rabbit antiserum against Mat fimbriae of E. coli was available from previous work (Pouttu et al., 2001). Bacteria were grown statically in glass flasks as planktonic cultures and collected by centrifugation. In order to investigate the effect of biofilm growth on Mat fimbriae expression, cells were also grown in the wells of PVC microtitre plates. The non-attached planktonic cells were first removed from the wells [referred to as surface-influenced planktonic (SIP) cells], and surface-attached biofilm cells were harvested from the wells after washing by scraping cells from the surface and resuspending them in PBS. The amount of Mat fimbriae on bacterial cells was assessed by whole-cell ELISA according to the procedure of de Ree et al. (1986). Briefly, bacterial cells were adjusted to equal concentrations by resuspending in PBS to an $\mathrm{OD}_{600}$ value of 0.25 , and microtitre plates (Nunc) were coated with $100 \mu$ l of the bacterial suspension per well and dried overnight at $37{ }^{\circ} \mathrm{C}$. The plates were then washed three times with PBS containing $0.05 \%$ Tween 20 (PBST) and wells were blocked with $100 \mu$ of PBS containing $2 \%$ BSA at room temperature for $2 \mathrm{~h}$. After washing three times with PBS-T, $100 \mu \mathrm{l}$ of anti-Mat fimbria antibodies diluted from $10^{-3}$ to $10^{-7}$ in PBS containing $1 \%$ Tween 20 (PBS-T2) was added to wells in duplicate and incubated at $37{ }^{\circ} \mathrm{C}$ for $2 \mathrm{~h}$. The plates were then washed three times with PBS-T, and $100 \mu \mathrm{l}$ of alkaline phosphataseconjugated swine anti-rabbit immunoglobulins (Dako) diluted 1:750 in PBS-T2 was added and incubated at room temperature for $2 \mathrm{~h}$. Finally, the plates were washed three times with PBS-T, $100 \mu \mathrm{l}$ phosphatase substrate (Sigma) at $1 \mathrm{mg} \mathrm{ml} \mathrm{m}^{-1}$ in diethanolamine/ magnesium chloride buffer (Reagena) was added and the absorbance at $405 \mathrm{~nm}$ of each well was measured after $30 \mathrm{~min}$ incubation at $37^{\circ} \mathrm{C}$ by an ELISA recorder (Multiskan EX, Thermo Scientific).

Indirect immunofluorescence. For detection of Mat fimbriae expression by indirect immunofluorescence as described by Pouttu et al. (2001), bacterial cells were suspended in PBS and immobilized on glass slides, fixed with $3.5 \%$ paraformaldehyde in PBS for $10 \mathrm{~min}$, washed and left to react for $30 \mathrm{~min}$ with anti-Mat fimbria antibodies diluted 1:50 in PBS containing 1\% BSA. After washing three times with PBS, the slides were incubated for 30 min with Alexa Fluor 488 goat anti-rabbit IgG (Invitrogen) diluted 1:1000 in PBS containing $1 \%$ BSA. After washing and mounting in Fluorescent Mounting Medium (Dako), the slides were examined in an epifluorescence microscope (Olympus BX50) equipped with a filter for FITC. The proportions of Mat-positive bacteria in six randomly chosen microscopic fields of $10^{3} \mu \mathrm{m}^{2}$ were determined.

Western blotting. Bacterial cells were adjusted to equal concentrations by resuspending in PBS to an $\mathrm{OD}_{600}$ of 0.8 . Pelleted cells from $750 \mu \mathrm{l}$ of the bacterial suspension were resuspended in $20 \mu \mathrm{H}_{2} \mathrm{O}$, HCl-treated with $2 \mu \mathrm{l} \mathrm{M} \mathrm{HCl}$, boiled for $2 \mathrm{~min}$ and neutralized with $2 \mu \mathrm{l} 1 \mathrm{M} \mathrm{NaOH}$. Denatured samples were mixed with half of their volume of SDS-PAGE loading buffer and boiled for $5 \mathrm{~min}$. Samples of $15 \mu$ were subjected to $12 \%$ SDS-PAGE, transferred onto a PVDF membrane (GE Healthcare) and then Mat fimbrial proteins were 
reacted with primary anti-Mat fimbria antibodies (diluted 1:500 in PBS containing $0.1 \%$ Tween 20), followed by the secondary peroxidase-conjugated anti-rabbit IgG $(1: 2500$; GE Healthcare), and enhanced chemiluminescence detection reagents (GE Healthcare) according to the manufacturer's instructions. To visualize the bands, the membrane was exposed to X-ray film (Agfa).

Serum agglutination. Bacterial agglutination in anti-Mat antiserum, diluted $10^{-2}$ in PBS, was performed on glass slides by a routine procedure (Rhen et al., 1983).

\section{RESULTS AND DISCUSSION}

\section{Effects of non-polar mutations on Mat expression}

The chromosomal $7 \mathrm{~kb}$ mat gene cluster of O18ac: $\mathrm{K} 1: \mathrm{H} 7$ meningitis isolate E. coli IHE 3034 contains six putative genes, of which mat $A, m a t B$ and $m a t C$ have earlier been shown to affect Mat fimbria biogenesis (Pouttu et al., 2001). mat $B$ (orthologues also known as $y a g Z$ and $\operatorname{ecp} A$ ) encodes the major fimbrillin, which is the only known structural element of the Mat fimbria (Pouttu et al., 2001). To define more precisely the genes of the mat cluster that participate in Mat fimbria biogenesis, we inactivated separately, by in-frame deletions, the entire matBCDEF region and each of these putative mat genes of the spontaneously Rif-resistant strain IHE 3034-Rif. Wholecell ELISA using polyclonal anti-Mat fimbria antiserum as primary antibodies showed a decreased surface expression of Mat fimbriae in the deletion mutant strains cultivated at $20{ }^{\circ} \mathrm{C}$ (Fig. 1a). As a negative control for Mat fimbriae expression, the analysis included the matB:: cat derivative of IHE 3034-Rif (Pouttu et al., 2001). Plasmids encoding MatB, MatC, MatD, MatE and MatF (Table 1) were used to complement the corresponding mat deletions, and the matBCDEF mutant strain was complemented by insertion of the genes back into the chromosomal deletion site. After growth at $20{ }^{\circ} \mathrm{C}$, each complemented strain showed a Mat expression level comparable to that of the wild-type strain (Fig. 1b) confirming that the individual mutations had no polar effects on expression. No Mat fimbriae were detected in bacteria grown at $37{ }^{\circ} \mathrm{C}$ (Fig. 1a, b, lower panels). These results indicated that the expression of the $m a t B-F$ genes is required for Mat fimbria biogenesis in E. coli IHE 3034, in addition to matA, which was shown by Pouttu et al. (2001) to be required for synthesis of Mat fimbriae.

\section{Biofilm formation by meningitis E. coli IHE 3034 involves Mat fimbriae}

The capacity of strain IHE 3034-Rif and its derivatives to form a monospecies biofilm on PVC plastic surfaces was quantified using CV staining of bacteria after $48 \mathrm{~h}$ static incubation in the biofilm-promoting M63 medium at 20 or $37^{\circ} \mathrm{C}$. High biofilm-forming ability is associated with asymptomatic bacteriuria E. coli strains (Ferrières et al., 2007); therefore the test included for comparison the strain ABU38, which in our previous work has proven to be (a)

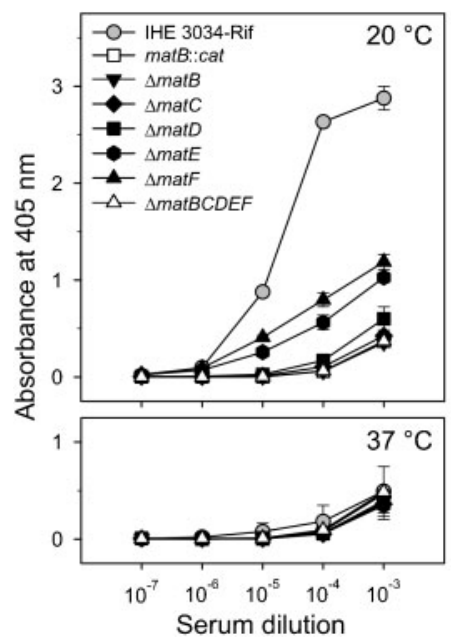

(b)

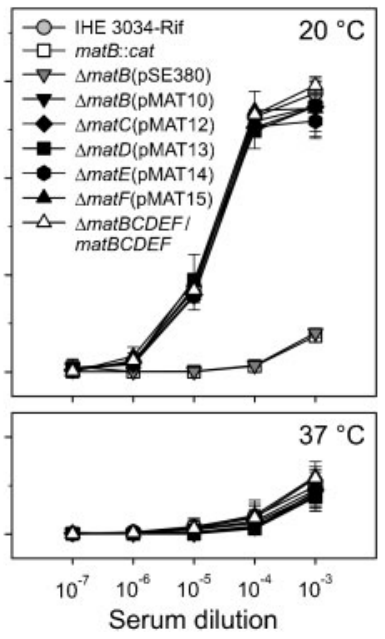

Fig. 1. Surface expression of Mat fimbriae by IHE 3034 strains. The parent strain IHE 3034-Rif, Mat fimbria-negative matB: : cat derivative, mat deletion mutants (a) and complemented mat deletion mutants (b) were grown in $\mathrm{LB}$ at $20^{\circ} \mathrm{C}$ (upper panels) or at $37{ }^{\circ} \mathrm{C}$ (lower panels) and analysed by whole-cell ELISA with anti-Mat fimbria serum as primary antibodies. The deleted genes and complementations are indicated in the inserts (upper panels). In the upper panel (a) $\triangle$ matBCDEF $(\triangle)$ overlaps with matB : : cat $(\square), \Delta$ matB $(\boldsymbol{\nabla})$ and $\triangle$ matC $(\boldsymbol{\nabla})$. The data represent means and standard deviations of two independent assays.

efficient in biofilm formation (unpublished). The commensal-like E. coli strain ABU38 belongs to phylogenetic lineage $\mathrm{B} 1$, has few virulence-associated genes and is unable to express type 1 fimbriae (Zdziarski et al., 2008). This strain also differs from strain IHE 3034 in Mat fimbriae expression, since no agglutination was detected with antiMat fimbria antiserum. The biofilm analysis demonstrated a strong biofilm formation by IHE 3034-Rif after growth at low temperature, but not at $37^{\circ} \mathrm{C}$, in contrast to the phenotype of ABU38 (Fig. 2a). Thus the mechanisms of biofilm production by the group B2 strain IHE 3034-Rif and the group B1 strain ABU38 are different. No biofilm was formed by the Mat fimbriae-deficient matBCDEF mutant strain (Fig. 2a, b) nor the individual mat deletion mutant strains (Fig. 2a). The apparent differences in biofilm-forming abilities are not due to the differential growth in the M63 medium, as the mutants exhibited growth rates comparable to that of the parent strain (data not shown). As shown in Fig. 2(a), single-copy chromosomal complementation of the matBCDEF deletion completely restored the biofilm-forming phenotype. When biofilm formation by IHE 3034-Rif was quantified over time at $20{ }^{\circ} \mathrm{C}$, a steady plateau was seen after $24 \mathrm{~h}$ of incubation, while ABU38 had already formed the highestdensity biofilm at $16 \mathrm{~h}$ and diminished thereafter (Fig. 2b). Parallel results were obtained when polystyrene was used as a template instead of PVC, whereas IHE 3034-Rif 
(a)

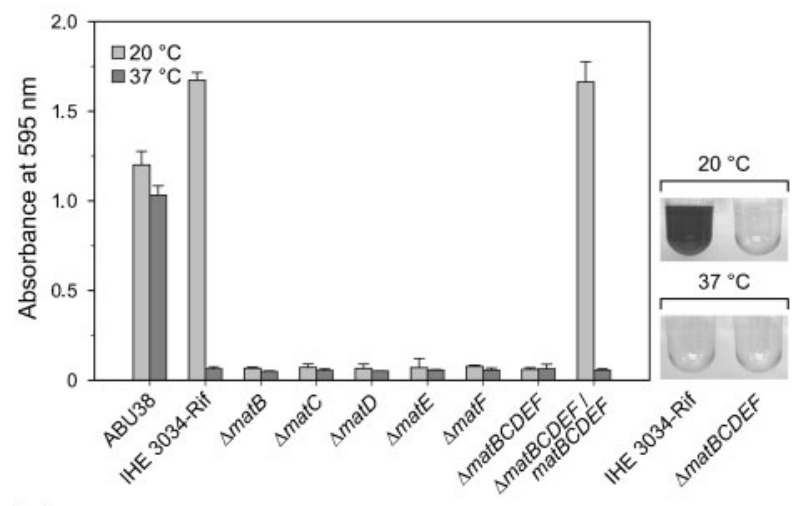

(b)

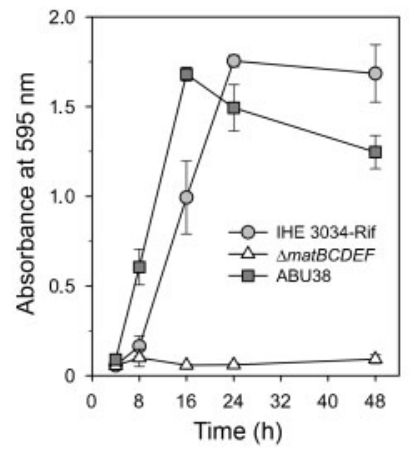

(c)

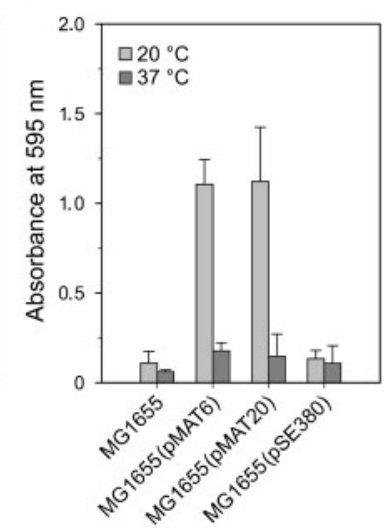

(d)
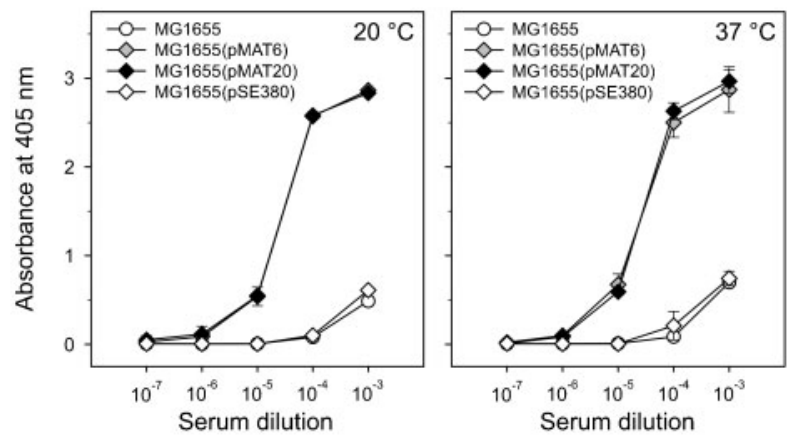

developed biofilm poorly on glass surfaces (data not shown), implying that biofilm formation by IHE 3034Rif is dependent on substratum hydrophobicity. Our results are in line with the recent observation that Mat fimbriae do not mediate biofilm formation on glass surfaces at $37{ }^{\circ} \mathrm{C}$ in the probiotic E. coli Nissle 1917 strain (Lasaro et al., 2009).

The mat operon in the genome of E. coli MG1655 (K-12) is $97.8 \%$ identical in sequence to that in the IHE 3034 genome, but MG1655 is incapable of Mat fimbriae expression in LB (Pouttu et al., 2001) or M63 medium (Fig. 2d). As expected, strain MG1655 had no ability to form a biofilm under the growth conditions employed in this study (Fig. 2c). To assess whether induced production
Fig. 2. Biofilm formation by IHE 3034-Rif and MG1655 mat derivatives. The biofilm-forming ability of the strain ABU38 is shown for comparison. Bacteria were grown in M63 medium in PVC microtitre plate wells, and biofilm-associated cells were visualized by $\mathrm{CV}$ staining. The data represent means and standard deviations of three independent experiments. (a) Biofilm formation by IHE 3034-Rif derivatives after growth for $48 \mathrm{~h}$ at 20 or $37{ }^{\circ} \mathrm{C}$. The left panel shows the quantification of biofilms and the right panels show representative samples of the macroscopic biofilm structures formed in the wells by IHE 3034-Rif and the Mat fimbriae-deficient matBCDEF mutant. (b) Kinetics of biofilm production during $48 \mathrm{~h}$ of growth at $20{ }^{\circ} \mathrm{C}$. (c) Quantification of biofilm formation by MG1655 derivatives after growth for $48 \mathrm{~h}$ at 20 or $37{ }^{\circ} \mathrm{C}$. (d) Induced Mat fimbriae expression of MG1655 derivatives after growth for $48 \mathrm{~h}$ in $\mathrm{M} 63$ medium at 20 or $37{ }^{\circ} \mathrm{C}$ analysed by whole-cell ELISA with anti-Mat fimbria serum as primary antibodies. The whole-cell ELISA data represent means and standard deviations of two independent assays.

of Mat fimbriae promotes formation of biofilm in the nonNMEC host MG1655, we introduced the plasmid pMAT6, encoding Mat fimbriae from IHE 3034, into MG1655. The overexpression from the plasmid resulted in the production of Mat fimbriae at both 20 and $37{ }^{\circ} \mathrm{C}$ (Fig. 2d) and biofilm growth at low temperature (Fig. 2c).

Comparison of the mat cluster sequence from MG1655 with IHE 3034 shows several non-synonymous nucleotides and hence amino acid variation in the predicted Mat proteins. Previous studies have demonstrated that the minor allelic variation of the type 1 fimbrial adhesin FimH affects tissue tropism through changes in the mannose receptor specificity (Pouttu et al., 1999; Sokurenko et al., 1995, 1998) and influences the ability to promote mannose-sensitive biofilm formation (Schembri \& Klemm, 2001). These findings prompted us to test the functional properties of the MG1655 Mat fimbria variant. The matBCDEF genes from MG1655 were cloned under the inducible $\operatorname{trc}$ promoter in pSE380. When the resulting plasmid pMAT20 was transformed into MG1655, we observed Mat fimbriae expression (Fig. 2d) and biofilm formation (Fig. 2c) equivalent to that detected in the strain harbouring pMAT6. The same result was obtained when the two plasmids were expressed separately in the IHE 3034-Rif or the IHE 3034 matBCDEF background (data not shown). The results show that there is no critical impact of the allelic variations on the function of the encoded proteins. Futhermore, the results illustrate that the mat genes are functional in MG1655, thus suggesting that the repression of Mat fimbriae expression in MG1655 is a consequence of differences in regulatory mechanisms, similar to the silencing of the highly conserved curli operons (Römling et al., 1998) in a large number of E. coli strains (Hammar et al., 1995; Olsén et al., 1993; Uhlich et al., 2001). Interestingly, despite the induced Mat expression, no clear biofilm formation was detected at $37^{\circ} \mathrm{C}$, indicating that under our test conditions the 
expression of Mat fimbriae is not enough for biofilm formation at $37^{\circ} \mathrm{C}$. Our results demonstrate that the presence of an expressed mat gene cluster is correlated with the ability of E. coli to produce a temperature-dependent biofilm, and we hypothesize that the lack of Mat-fimbriaedependent biofilm at $37{ }^{\circ} \mathrm{C}$ results from downregulation of other surface structures (White-Ziegler et al., 2008) interacting with the Mat fimbriae. These factors remain to be identified.

\section{Flagella and other fimbriae of IHE $\mathbf{3 0 3 4}$ are not critical for biofilm formation at low temperature}

Strain IHE 3034 expresses the mannoside-binding type 1 fimbriae, the sialic acid-binding S-fimbriae and flagella (Selander et al., 1986) in addition to Mat fimbriae. Since various $E$. coli surface structures participate in biofilm formation (Van Houdt \& Michiels, 2005), we compared surface filaments for their impact on biofilm formation by IHE 3034-Sm. No change in biofilm formation was observed by the single type 1 fimbrial fimA, S-fimbrial $s f a A$ or flagellar fliC mutants, or with the fimA sfaA fliC triple mutant. However, the fimA sfaA fliC matB derivative, also deficient in Mat fimbriae production, failed to form a biofilm (Fig. 3), indicating that under these test conditions Mat fimbriae are a principal mediator of biofilm formation by IHE 3034 .

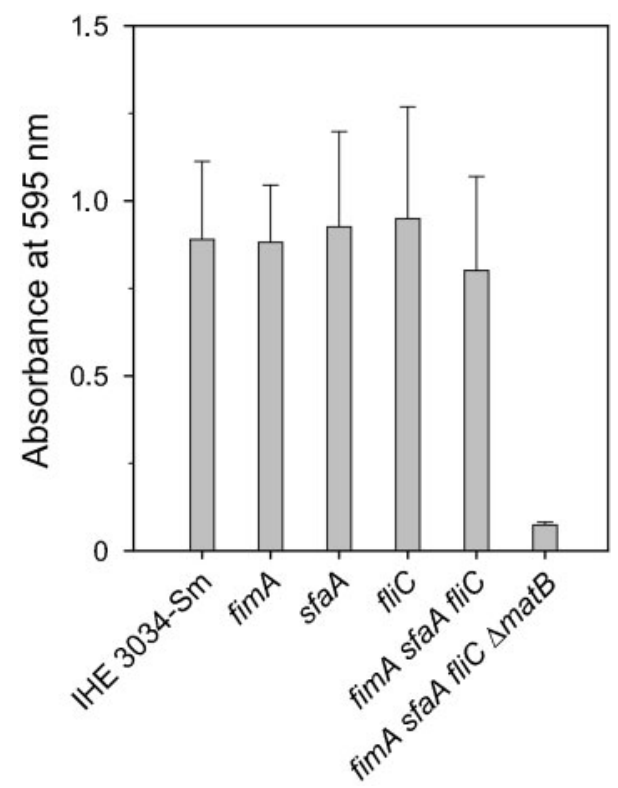

Fig. 3. Biofilm formation by IHE 3034 surface filament mutants. The parental strain IHE 3034-Sm and surface filament mutants (type 1 fimbrial fimA, S-fimbrial $s f a A$, flagellar fliC and Mat fimbrial mat $B$ ) were grown for $48 \mathrm{~h}$ at $20^{\circ} \mathrm{C}$ in M63 medium in PVC microtitre plates and the biofilm formation was quantified with $\mathrm{CV}$. The data represent means and standard deviations of three independent experiments.

\section{Mat fimbriae affect early stages of biofilm development and are present in mature biofilms}

Biofilm formation initiates as surface attachment and then proceeds to a complex architecture of cell interactions (Stoodley et al., 2002). We next determined the initial attachment of IHE 3034-Rif derivatives onto a PVC surface, first by using the CV-staining method with $1 \mathrm{~h}$ incubation time at $20{ }^{\circ} \mathrm{C}$. At low bacterial density, both the wild-type and the matBCDEF mutant adhered weakly and no difference was seen between the strains (Fig. 4a), whereas the adherence at higher bacterial density enabled the wild-type IHE 3034-Rif to bind efficiently on the PVC surface. Similar results were obtained by indirect immunofluorescence microscopy analysis of PVC tabs incubated with low-density bacterial suspensions. At early time points $(\leqslant 1 \mathrm{~h})$, the attachment of the matBCDEF mutant was indistinguishable from that of the wild-type strain (Fig. $4 \mathrm{~b})$. However, after $3 \mathrm{~h}$, a difference between the wild-type and mutant became evident. Over time, IHE 3034-Rif formed a progressively denser layer of cells on the PVC surface, whereas the attachment of the matBCDEF mutant remained unchanged, indicating that the mutant was defective in irreversible attachment and thus biofilm formation.

Expression of Mat fimbriae is evidently regulated by phase variation (Pouttu et al., 2001), an adaptive strategy to switch on and off the expression, leading to cell-to-cell variability in a population. The majority of the IHE 3034Rif cells cultured statically in M63 medium and used to inoculate the wells with PVC tabs were Mat-fimbriated $(69.6 \pm 2.0 \%)$, and no accumulation of Mat-positive cells was observed during the initial attachment experiment (Fig. 4b). Interestingly, these frequencies of Mat fimbriaeexpressing cells were markedly higher than the frequencies observed earlier with IHE 3034-Rif cells cultured in LB (Pouttu et al., 2001), suggesting that the adjustment of the balance between the two fimbriation states responds to environmental signals. This may be responsible for the $\sim 50 \%$ lower level of biofilm formation when M63 was replaced with LB as a growth medium (data not shown).

Formation of a biofilm involves coordinate multifactorial reprogramming of gene expression, including induction or downregulation of fimbriae genes (Domka et al., 2007; Hancock \& Klemm, 2007; Schembri et al., 2003). We next assessed whether Mat fimbriae are differentially expressed in sessile biofilm cells of IHE 3034-Rif and their planktonic counterparts. The cells from a glass flask, a substratum that does not support biofilm formation by IHE 3034-Rif, were used as a reference, as an inoculum, and were defined as 'inoculate' cells; the cells in the glass flasks at the end of the incubation periods were termed 'planktonic' cells. The non-attached cells removed from the PVC wells after biofilm growth were defined as 'surface-influenced planktonic (SIP)' cells, according to Steyn et al. (2001), and the surface-attached cells harvested from the walls of the PVC wells were termed 'biofilm' cells (see Methods). After 24 or 
(a)

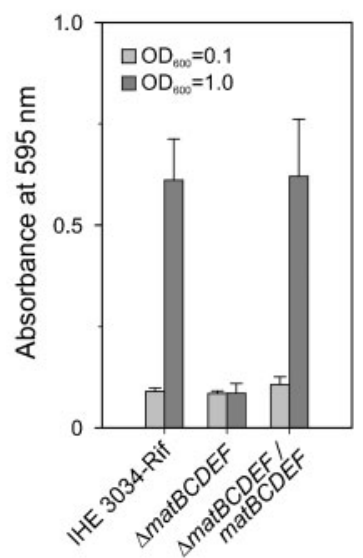

(b)

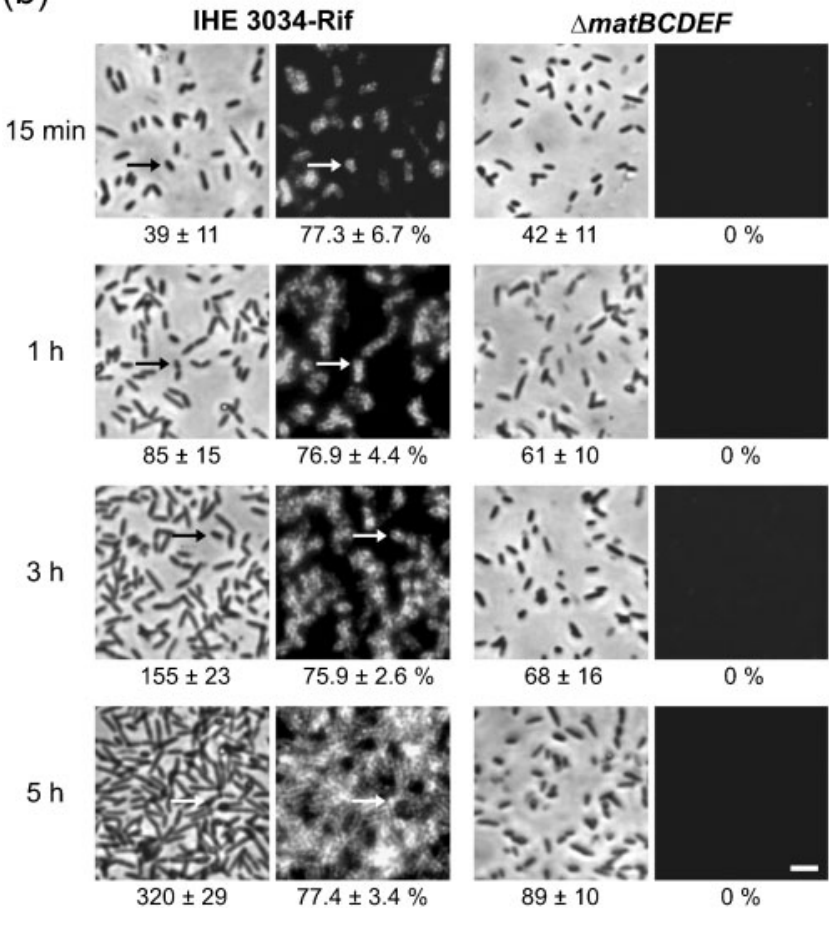

$48 \mathrm{~h}$ of static growth in $\mathrm{M} 63$ medium at $20{ }^{\circ} \mathrm{C}$, the mean Mat expression levels of the entire cell populations were quantified by whole-cell ELISA. No changes in the surface expression of Mat fimbriae were apparent on IHE 3034-Rif cells harvested from the different modes of growth (Fig. $5 a)$. We also analysed the cell samples by immunoblotting with anti-Mat antibodies to detect both surface expressed and intracellular fimbrial proteins. Consistent with the ELISA results, the $18 \mathrm{kDa}$ band of the major fimbrillin MatB, corresponding to the calculated molecular mass of mature MatB (Pouttu et al., 2001), was expressed in similar amounts in all IHE 3034-Rif samples (Fig. 5b). Similarly, examination of the IHE 3034-Rif cell populations by indirect immunofluorescence microscopy with anti-Mat fimbriae antiserum was in line with these and the initial
Fig. 4. Initial attachment and Mat fimbriae expression of $\mathrm{IHE}$ 3034-Rif derivatives onto PVC surfaces. (a) Quantification of initial attachment in the PVC microtitre plate wells by CV staining. Bacteria were adjusted in M63 medium to low or high density $\left(O D_{600} 0.1\right.$ or 1.0 , respectively) and incubated in the wells for $1 \mathrm{~h}$ at $20{ }^{\circ} \mathrm{C}$. The data represent means and standard deviations of three independent experiments. (b) Indirect immunofluorescence microscopy analysis of the initial biofilm formation using primary antibodies directed against Mat fimbriae. The bacteria were adjusted in $\mathrm{M} 63$ medium to low density $\left(\mathrm{OD}_{600} 0.1\right)$ and incubated at $20{ }^{\circ} \mathrm{C}$ in microtitre plates containing PVC tabs. At the indicated time points, tabs were removed and cells were fixed, immunostained and examined by epifluorescence microscopy. Representative microscopy fields of phase-contrast (left panels) and epifluorescence images (right panels) are shown, and the mean number of attached bacteria (left panels) and the proportion of Mat fimbriated bacteria (right panels) \pm SD in 20 and 6 randomly chosen fields of $10^{3} \mu \mathrm{m}^{2}$, respectively, is indicated below the images. Arrows indicate adherent, Mat fimbriated bacteria. Scale bar, $5 \mu \mathrm{m}$.

(a)
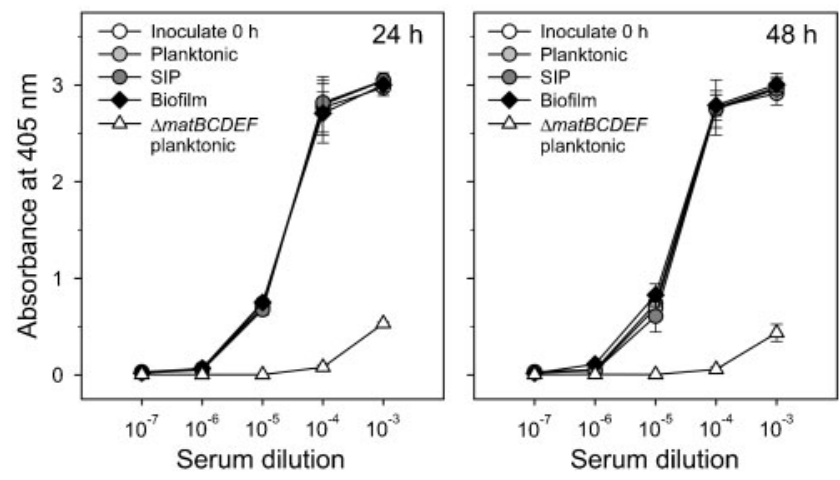

(b)

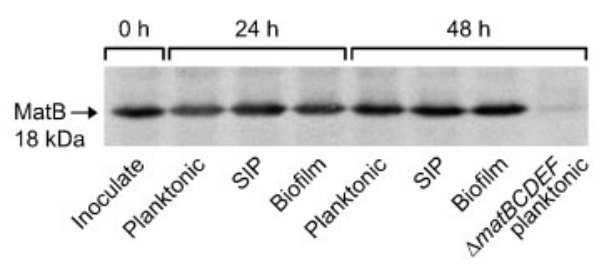

Fig. 5. Biofilm formation and Mat fimbriae expression by $\mathrm{IHE}$ 3034-Rif and the matBCDEF deletion mutant. Expression of Mat fimbriae in planktonic, surface-influenced planktonic (SIP) and biofilm cells of IHE 3034-Rif was analysed by whole-cell ELISA (a) and Western blotting of $\mathrm{HCl}$-treated cellular proteins (b) with antiMat fimbria serum as primary antibodies after growth for $24 \mathrm{~h}$ or for $48 \mathrm{~h}$ in $\mathrm{M} 63$ medium at $20^{\circ} \mathrm{C}$. The whole-cell ELISA data represent means and standard deviations of three independent experiments. Western blotting was assessed twice, and a representative blot is shown. 
attachment results, as 74 to $83 \%$ of the cells in the populations expressed the fimbriae (data not shown).

\section{Conclusion}

The E. coli strains IHE 3034 and ABU38 differ in Mat fimbriae expression and form biofilms that vary in temperature sensitivity. This is a further indication that E. coli isolates use multiple mechanisms for biofilm formation (Beloin et al., 2008; Van Houdt \& Michiels, 2005). We (Pouttu et al., 2001) and others (Rendón et al., 2007) have found that Mat fimbriae represent the most common fimbrial type in E. coli and that the mat genes in E. coli of different origin are highly conserved (97 to $98 \%$ nucleotide sequence identity). This suggests that the Mat fimbria represents an ancestral fimbrial type in E. coli and that its functions are essential for $E$. coli as a species, although still poorly described. The current data indicate that the regulation of Mat fimbriae in different clonal groups of E. coli is variable. Enterohaemorrhagic, enterotoxigenic and enteropathogenic E. coli strains were shown to produce the fimbriae after growth at $37^{\circ} \mathrm{C}$ in tissue culture medium, suggesting that intestinal E. coli strains may express the fimbriae in the human intestine (Blackburn et al., 2009; Rendón et al., 2007; Saldaña et al., 2009). Our ongoing studies indicate that IHE 3034 also is able to express the fimbriae at $37^{\circ} \mathrm{C}$, albeit under differential growth conditions (T. A. Lehti, unpublished). The central mechanism for Mat fimbriae expression in IHE 3034 is currently under investigation. Recently, Lasaro et al. (2009) reported that the Mat fimbria homologue of the probiotic E. coli strain Nissle 1917 is essential for intestinal colonization of the infant mouse. In the mucosal habitats of E. coli, multispecies biofilm communities are present on the gut (Palestrant et al., 2004) and vaginal (Swidsinski et al., 2005) epithelia and there is evidence for the in vivo community behaviour of commensal and pathogenic E. coli (Macfarlane \& Macfarlane, 2006; Rosen et al., 2007), suggesting that the structured lifestyle contributes both to normal ecology and to pathogenicity of E. coli in the host. Furthermore, the ability of E. coli to grow protective biofilms on non-host targets in heterogeneous environmental niches arguably ensures continual transmission to human populations. The results presented in this study show that the expression of the ubiquitous mat fimbrial operon enables E. coli to display multicellular behaviour at low temperatures. It remains to be established whether Mat-mediated biofilm formation plays a role in environmental survival and/or in host colonization by E. coli.

\section{ACKNOWLEDGEMENTS}

We thank Raili Lameranta, Terhi Miikkulainen, Teija Ojala and Laura Teirilä for technical assistance. P. B. received a Research Fellowship from the Bavarian Research Foundation. This work was financially supported by the European Network of Excellence EuroPathoGenomics (grant number CEE LSHB-CT-2005-512061), the Viikki Graduate School in Molecular Biosciences, the Academy of Finland and the German Federal
Ministry of Education and Research in the frame of the ERA-NET PathoGenoMics (grant numbers 1118982, 130202 and 0313937A, respectively) and the Academy of Finland (grants numbers 116507 and 1123900).

\section{REFERENCES}

Adlerberth, I. \& Wold, A. E. (2009). Establishment of the gut microbiota in western infants. Acta Paediatr 98, 229-238.

Beloin, C., Roux, A. \& Ghigo, J. M. (2008). Escherichia coli biofilms. Curr Top Microbiol Immunol 322, 249-289.

Blackburn, D., Husband, A., Saldaña, Z., Nada, R. A., Klena, J., Qadri, F. \& Girón, J. A. (2009). Distribution of the Escherichia coli common pilus among diverse strains of human enterotoxigenic E. coli. J Clin Microbiol 47, 1781-1784.

Blattner, F. R., Plunkett, G., III, Bloch, C. A., Perna, N. T., Burland, V., Riley, M., Collado-Vides, J., Glasner, J. D., Rode, C. K. \& other authors (1997). The complete genome sequence of Escherichia coli K12. Science 277, 1453-1462.

de Ree, J. M., Schwillens, P. \& van den Bosch, J. F. (1986). Monoclonal antibodies for serotyping the $\mathrm{P}$ fimbriae of uropathogenic Escherichia coli. J Clin Microbiol 24, 121-125.

Dobrindt, U. (2005). (Patho-)genomics of Escherichia coli. Int J Med Microbiol 295, 357-371.

Domka, J., Lee, J., Bansal, T. \& Wood, T. K. (2007). Temporal geneexpression in Escherichia coli K-12 biofilms. Environ Microbiol 9, 332346.

Donnenberg, M. S. \& Kaper, J. B. (1991). Construction of an eae deletion mutant of enteropathogenic Escherichia coli by using a positive-selection suicide vector. Infect Immun 59, 4310-4317.

Ferrières, L., Hancock, V. \& Klemm, P. (2007). Biofilm exclusion of uropathogenic bacteria by selected asymptomatic bacteriuria Escherichia coli strains. Microbiology 153, 1711-1719.

Genevaux, P., Muller, S. \& Bauda, P. (1996). A rapid screening procedure to identify mini-Tn 10 insertion mutants of Escherichia coli K-12 with altered adhesion properties. FEMS Microbiol Lett 142, 2730 .

Ghigo, J. M. (2001). Natural conjugative plasmids induce bacterial biofilm development. Nature 412, 442-445.

Hall-Stoodley, L., Costerton, J. W. \& Stoodley, P. (2004). Bacterial biofilms: from the natural environment to infectious diseases. Nat Rev Microbiol 2, 95-108.

Hammar, M., Arnqvist, A., Bian, Z., Olsén, A. \& Normark, S. (1995). Expression of two csg operons is required for production of fibronectin- and congo red-binding curli polymers in Escherichia coli K-12. Mol Microbiol 18, 661-670.

Hancock, V. \& Klemm, P. (2007). Global gene expression profiling of asymptomatic bacteriuria Escherichia coli during biofilm growth in human urine. Infect Immun 75, 966-976.

Lasaro, M. A., Salinger, N., Zhang, J., Wang, Y., Zhong, Z., Goulian, M. \& Zhu, J. (2009). F1C fimbriae play an important role in biofilm formation and intestinal colonization by the Escherichia coli commensal strain Nissle 1917. Appl Environ Microbiol 75, 246-251.

Lindberg, U., Hanson, L. A., Jodal, U., Lidin-Janson, G., Lincoln, K. \& Olling, S. (1975). Asymptomatic bacteriuria in schoolgirls. II. differences in Escherichia coli causing asymptomatic bacteriuria. Acta Paediatr Scand 64, 432-436.

Macfarlane, S. \& Macfarlane, G. T. (2006). Composition and metabolic activities of bacterial biofilms colonizing food residues in the human gut. Appl Environ Microbiol 72, 6204-6211. 
Miller, V. L. \& Mekalanos, J. J. (1988). A novel suicide vector and its use in construction of insertion mutations: osmoregulation of outer membrane proteins and virulence determinants in Vibrio cholerae requires toxR. J Bacteriol 170, 2575-2583.

Mobley, H. L., Jarvis, K. G., Elwood, J. P., Whittle, D. I., Lockatell, C. V., Russell, R. G., Johnson, D. E., Donnenberg, M. S. \& Warren, J. W. (1993). Isogenic P-fimbrial deletion mutants of pyelonephritogenic Escherichia coli: the role of $\alpha \mathrm{Gal}(1-4) \beta \mathrm{Gal}$ binding in virulence of a wild-type strain. Mol Microbiol 10, 143-155.

Nowrouzian, F. L., Wold, A. E. \& Adlerberth, I. (2005). Escherichia coli strains belonging to phylogenetic group B2 have superior capacity to persist in the intestinal microflora of infants. J Infect Dis 191, 10781083.

Obata-Yasuoka, M., Ba-Thein, W., Tsukamoto, T., Yoshikawa, H. \& Hayashi, H. (2002). Vaginal Escherichia coli share common virulence factor profiles, serotypes and phylogeny with other extraintestinal $E$. coli. Microbiology 148, 2745-2752.

Ochman, H. \& Selander, R. K. (1984). Evidence for clonal population structure in Escherichia coli. Proc Natl Acad Sci U S A 81, 198-201.

Olsén, A., Arnqvist, A., Hammar, M., Sukupolvi, S. \& Normark, S. (1993). The RpoS sigma factor relieves H-NS-mediated transcriptional repression of $\operatorname{csg} A$, the subunit gene of fibronectin-binding curli in Escherichia coli. Mol Microbiol 7, 523-536.

O'Toole, G. A. \& Kolter, R. (1998). Initiation of biofilm formation in Pseudomonas fluorescens WCS365 proceeds via multiple, convergent signalling pathways: a genetic analysis. Mol Microbiol 28, 449-461.

Palestrant, D., Holzknecht, Z. E., Collins, B. H., Parker, W., Miller, S. E. \& Bollinger, R. R. (2004). Microbial biofilms in the gut: visualization by electron microscopy and by acridine orange staining. Ultrastruct Pathol 28, 23-27.

Pardee, A. B., Jacob, F. \& Monod, J. (1959). The genetic control and cytoplasmic expression of "inducibility" in the synthesis of $\beta$ galactosidase by E. coli. J Mol Biol 1, 165-178.

Picard, B., Garcia, J. S., Gouriou, S., Duriez, P., Brahimi, N., Bingen, E., Elion, J. \& Denamur, E. (1999). The link between phylogeny and virulence in Escherichia coli extraintestinal infection. Infect Immun 67, 546-553.

Pouttu, R., Puustinen, T., Virkola, R., Hacker, J., Klemm, P. \& Korhonen, T. K. (1999). Amino acid residue ala-62 in the FimH fimbrial adhesin is critical for the adhesiveness of meningitisassociated Escherichia coli to collagens. Mol Microbiol 31, 1747-1757.

Pouttu, R., Westerlund-Wikström, B., Lång, H., Alsti, K., Virkola, R., Saarela, U., Siitonen, A., Kalkkinen, N. \& Korhonen, T. K. (2001). matB, a common fimbrillin gene of Escherichia coli, expressed in a genetically conserved, virulent clonal group. J Bacteriol 183, 47274736.

Pratt, L. A. \& Kolter, R. (1998). Genetic analysis of Escherichia coli biofilm formation: roles of flagella, motility, chemotaxis and type I pili. Mol Microbiol 30, 285-293.

Reisner, A., Haagensen, J. A., Schembri, M. A., Zechner, E. L. \& Molin, S. (2003). Development and maturation of Escherichia coli K12 biofilms. Mol Microbiol 48, 933-946.

Rendón, M. A., Saldaña, Z., Erdem, A. L., Monteiro-Neto, V., Vázquez, A., Kaper, J. B., Puente, J. L. \& Girón, J. A. (2007). Commensal and pathogenic Escherichia coli use a common pilus adherence factor for epithelial cell colonization. Proc Natl Acad Sci U S A 104, 1063710642.

Rhen, M., Knowles, J., Penttilä, M. E., Sarvas, M. \& Korhonen, T. K. (1983). P fimbriae of Escherichia coli: molecular cloning of DNA fragments containing the structural genes. FEMS Microbiol Lett 19, $119-123$.
Römling, U., Bian, Z., Hammar, M., Sierralta, W. D. \& Normark, S. (1998). Curli fibers are highly conserved between Salmonella typhimurium and Escherichia coli with respect to operon structure and regulation. J Bacteriol 180, 722-731.

Rosen, D. A., Hooton, T. M., Stamm, W. E., Humphrey, P. A. \& Hultgren, S. J. (2007). Detection of intracellular bacterial communities in human urinary tract infection. PLoS Med 4, e329.

Russo, T. A. \& Johnson, J. R. (2000). Proposal for a new inclusive designation for extraintestinal pathogenic isolates of Escherichia coli: ExPEC. J Infect Dis 181, 1753-1754.

Saldaña, Z., Erdem, A. L., Schüller, S., Okeke, I. N., Lucas, M., Sivananthan, A., Phillips, A. D., Kaper, J. B., Puente, J. L. \& Girón, J. A. (2009). The Escherichia coli common pilus and the bundle-forming pilus act in concert during the formation of localized adherence by enteropathogenic E. coli. J Bacteriol 191, 3451-3461.

Sambrook, J. \& Russell, D. W. (2001). Molecular Cloning: a Laboratory Manual, 3rd edn. Cold Spring Harbor, NY: Cold Spring Harbor Laboratory.

Sarff, L. D., McCracken, G. H., Schiffer, M. S., Glode, M. P., Robbins, J. B., Ørskov, I. \& Ørskov, F. (1975). Epidemiology of Escherichia coli $\mathrm{K} 1$ in healthy and diseased newborns. Lancet 1, 1099-1104.

Savageau, M. A. (1983). Escherichia coli habitats, cell types, and molecular mechanisms of gene control. Am Nat 122, 732-744.

Schembri, M. A. \& Klemm, P. (2001). Biofilm formation in a hydrodynamic environment by novel FimH variants and ramifications for virulence. Infect Immun 69, 1322-1328.

Schembri, M. A., Kjærgaard, K. \& Klemm, P. (2003). Global gene expression in Escherichia coli biofilms. Mol Microbiol 48, 253267.

Selander, R. K., Korhonen, T. K., Väisanen-Rhen, V., Williams, P. H., Pattison, P. E. \& Caugant, D. A. (1986). Genetic relationships and clonal structure of strains of Escherichia coli causing neonatal septicemia and meningitis. Infect Immun 52, 213-222.

Siitonen, A. (1992). Escherichia coli in fecal flora of healthy adults: serotypes, $\mathrm{P}$ and type $1 \mathrm{C}$ fimbriae, non-P mannose-resistant adhesins, and hemolytic activity. J Infect Dis 166, 1058-1065.

Simon, R., Priefer, U. \& Pühler, A. (1983). A broad host range mobilization system for in vivo genetic engineering: transposon mutagenesis in gram-negative bacteria. Biotechnology 1, 784-791.

Sokurenko, E. V., Courtney, H. S., Maslow, J., Siitonen, A. \& Hasty, D. L. (1995). Quantitative differences in adhesiveness of type 1 fimbriated Escherichia coli due to structural differences in fimH genes. J Bacteriol 177, 3680-3686.

Sokurenko, E. V., Chesnokova, V., Dykhuizen, D. E., Ofek, I., Wu, X. R., Krogfelt, K. A., Struve, C., Schembri, M. A. \& Hasty, D. L. (1998). Pathogenic adaptation of Escherichia coli by natural variation of the FimH adhesin. Proc Natl Acad Sci U S A 95, 8922-8926.

Steyn, B., Oosthuizen, M. C., MacDonald, R., Theron, J. \& Brözel, V. S. (2001). The use of glass wool as an attachment surface for studying phenotypic changes in Pseudomonas aeruginosa biofilms by twodimensional gel electrophoresis. Proteomics 1, 871-879.

Stoodley, P., Sauer, K., Davies, D. G. \& Costerton, J. W. (2002). Biofilms as complex differentiated communities. Annu Rev Microbiol 56, 187-209.

Swidsinski, A., Mendling, W., Loening-Baucke, V., Ladhoff, A., Swidsinski, S., Hale, L. P. \& Lochs, H. (2005). Adherent biofilms in bacterial vaginosis. Obstet Gynecol 106, 1013-1023.

Uhlich, G. A., Keen, J. E. \& Elder, R. O. (2001). Mutations in the $\operatorname{csg} D$ promoter associated with variations in curli expression in certain strains of Escherichia coli O157 : H7. Appl Environ Microbiol 67, 23672370. 
Van Houdt, R. \& Michiels, C. W. (2005). Role of bacterial cell surface structures in Escherichia coli biofilm formation. Res Microbiol 156, 626-633.

Vidal, O., Longin, R., Prigent-Combaret, C., Dorel, C., Hooreman, M. \& Lejeune, P. (1998). Isolation of an Escherichia coli K-12 mutant strain able to form biofilms on inert surfaces: involvement of a new $o m p R$ allele that increases curli expression. J Bacteriol 180, 2442-2449.

White-Ziegler, C. A., Um, S., Pérez, N. M., Berns, A. L., Malhowski, A. J. \& Young, S. (2008). Low temperature $\left(23{ }^{\circ} \mathrm{C}\right)$ increases expression of biofilm-, cold-shock- and RpoS-dependent genes in Escherichia coli K-12. Microbiology 154, 148-166.
Wood, T. K., Gonzalez Barrios, A. F., Herzberg, M. \& Lee, J. (2006). Motility influences biofilm architecture in Escherichia coli. Appl Microbiol Biotechnol 72, 361-367.

Zdziarski, J., Svanborg, C., Wullt, B., Hacker, J. \& Dobrindt, U. (2008). Molecular basis of commensalism in the urinary tract: low virulence or virulence attenuation? Infect Immun 76, 695-703.

Zhang, L., Foxman, B. \& Marrs, C. (2002). Both urinary and rectal Escherichia coli isolates are dominated by strains of phylogenetic group B2. J Clin Microbiol 40, 3951-3955.

Edited by: D. Demuth 